\title{
O "LUGAR" EDUCAÇÃO INFANTIL: AS INFÂNCIAS E A CONTEMPORANEIDADE
}

\author{
THE EARLY CHILDHOOD EDUCATION "PLACE": THE CHILDHOODS AND THE \\ CONTEMPORANEITY
}

\author{
DCleonice Lazzarotto \\ Mestre em Educação \\ Universidade Comunitária da Região de Chapecó - UNOCHAPECÓ \\ Chapecó, SC - Brasil \\ cleolazzarotto@unochapeco.edu.br \\ Luci dos Santos Bernardi \\ Doutora em Educação Científica e Tecnológica \\ Universidade Regional Integrada do Alto Uruguai e das Missões - URI/FW \\ Chapecó, SC - Brasil \\ lucisantosbernardi@gmail.com
}

\begin{abstract}
Resumo: Este estudo tem por objetivo refletir sobre como as concepções de infância e criança instituíram-se ao longo da história, entrelaçando-se com as transformações sociais e com a constituição das instituições educativas, tomando a infância como constructo social e buscando compreender seu lugar na contemporaneidade. Trata-se de uma discussão teórica, que conceitua lugar para além de mera localização geográfica e o define como espaço do vivido, da experiência e das interações sociais, amparando-se nos estudos de Tuan (2013) e Augé (2012). Partindo desse viés, emerge a possibilidade de pensar a Educação Infantil na contemporaneidade como "lugar" de experiência, fundamentando-se nos pressupostos de Larossa $(2011,2017)$ e Agamben (2005), como espaços educativos que oportunizem novos olhares e sentidos sobre as infâncias, de modo que a criança seja valorizada em sua singularidade, podendo expressar-se sobre si e ser reconhecida enquanto sujeito social.
\end{abstract}

Palavras-chave: contemporaneidade; educação infantil; infância; experiência; lugar.

Abstract: This article reflects about how the conceptions of childhood and child were instituted along the History, intertwined with social transformations and the constitution of the educational institutions. In this paper, the childhood is understood as a social construct and seeks out to investigate its place in the contemporaneity. It is a theoretical discussion that conceptualizes "place" besides the geographic location, defining it as a space of the lived, as experience, and social interaction, based on Tuan (2013) and Augé (2012). From this perspective, it is possible to reflect about early childhood education in contemporaneity as a "place" of experience, based on Larossa (2011, 2017) and Agamben (2005) thoughts. The "place" of experience is an educational space that accepts new meanings for the childhood. Thus, the child's singularity is value, being able to express themselves and be recognized as a social subject.

Keywords: contemporaneity; early childhood education; childhood; experience; place.

\section{Para citar - (ABNT NBR 6023:2018)}

LAZZAROTTO, Cleonice; BERNARDI, Luci dos Santos. O "lugar" educação infantil: as infâncias e a contemporaneidade. Eccos - Revista Científica, São Paulo, n. 59, p. 1-15, e13522, out./dez. 2021. Disponível em: https://doi.org/10.5585/eccos.n59.13522. 


\section{Introdução}

Como a infância e a criança têm sido pensadas no imaginário social? Que atravessamentos históricos e sociais estão presentes na concepção de infância e de criança? Como a criança contemporânea vive a sua infância? Como a Educação Infantil tem tratado a infância?

Esses são alguns dos questionamentos que nos instigam a refletir sobre a emergência do conceito de infância e de criança ao longo da história, bem como a compreender que resquícios das concepções do passado ainda têm seus reflexos na atualidade, especialmente no que se refere à universalização e à naturalização da ideia de infância.

Tomando a infância como constructo social e buscando compreender seu lugar na atualidade, considera-se pertinente apresentar um breve recorte sobre as principais transformações emergentes na sociedade contemporânea, retratando novas significações em relação ao tempo e ao lugar. Portanto, num primeiro momento, amparando-se nos estudos de Tuan (2013) e Augé (2012), colocamos em evidência o conceito de lugar como espaço de múltiplas experiências, aproximando-se dos pressupostos de Larrosa (2002).

Na sequência, apresenta-se uma retomada histórica sobre as concepções de infância e de criança, de modo a localizar seu lugar na contemporaneidade. Por fim, reconhecendo a pluralidade de infâncias e compreendendo a criança como sujeito histórico e social, atribui-se importância à Educação Infantil como lugar de experiência e produção de sentidos, a partir dos estudos de Larrosa $(2011,2017)$ e Agamben (2005), lançando novos olhares e sentidos sobre o ser criança e sobre as relações sociais.

\section{Lugar: entrecruzamento de percursos e discursos}

Conforme afirma Agamben (2009), a contemporaneidade apresenta-se sob diversas temporalidades, uma vez que “[...] é uma singular relação com o próprio tempo, que adere a este e, ao mesmo tempo, toma distâncias; mais precisamente, essa é a relação com o tempo que a este adere através de uma dissociação e um anacronismo" (p. 59, grifo do autor). Em outras palavras, é o tempo da ambivalência, pois, do mesmo modo em que sentimos a necessidade de assumir algumas determinações e formas de vida presentes na atualidade, é preciso também nos colocarmos à margem, produzindo o estranhamento e um olhar crítico sobre este novo contexto.

O etnólogo e antropólogo francês Marc Augé (2012) caracteriza a sociedade contemporânea pela emergência do excesso em três transformações principais. A primeira delas se refere a um novo entendimento da categoria de tempo, tanto em relação à percepção quanto 
ao uso que fazemos dele. De acordo com o estudioso, a história tem passado por um processo de aceleramento em virtude do excesso de informações e de acontecimentos, na maioria das vezes, imprevisíveis, ao ponto de a superabundância dos fatos levar à necessidade diária de atribuirmos sentido ao presente, ao mundo atual, e não mais à historicidade dos fatos.

A segunda transformação, própria da contemporaneidade, relaciona-se ao espaço. Em vias terrestres, os meios de transporte acelerados têm encurtado as distâncias, favorecendo novas redes de contato. Paralelamente, a era espacial tem assinalado um processo intenso de mudanças e velocidade, haja vista que imagens do mundo inteiro, transmitidas por satélites, chegam até nós a todo instante, permitindo-nos acessá-las, além de facilitar nossa aproximação com os diferentes acontecimentos. Apesar dessa facilidade, Augé (2012) chama a atenção para as distorções possíveis das informações e do uso inadequado das imagens: "Essa superabundância espacial funciona como uma isca, mas uma isca cujo manipulador teríamos dificuldade em identificar (tudo não passa de miragem)" (p. 35). Em decorrência dessa multiplicidade de imagens e informações, o mesmo autor sinaliza a necessidade do sujeito contemporâneo "[...] reaprender a pensar o espaço" (p. 37).

A terceira transformação gerada pelo excesso corresponde ao individualismo. Isso porque as referências coletivas têm se tornado frágeis devido às características egóicas do sujeito, ou seja, “[...] o indivíduo quer um mundo para ser um mundo. Ele pretende interpretar por e para si mesmo as informações que lhe são entregues" (AUGÉ, 2012, p. 38).

Para Bauman (2001), na sociedade contemporânea, a qual denomina modernidade líquida ${ }^{1}$, vêm emergindo a liquefação das funções sociais, a privatização e a individualização do sujeito, a fluidez dos valores, a superficialidade das relações, como também a rapidez das informações.

[...] O 'derretimento dos sólidos', traço permanente da modernidade, adquiriu, portanto, um novo sentido, e, mais que tudo, foi redirecionado a um novo alvo, e um dos principais efeitos desse redirecionamento foi a dissolução das forças que poderiam ter mantido a questão da ordem e do sistema na agenda política. Os sólidos que estão para ser lançados no cadinho e os que estão derretendo neste momento, o momento da modernidade fluida, são os elos que entrelaçam as escolhas individuais em projetos e ações coletivas - os padrões de comunicação e coordenação entre as políticas de vida conduzidas individualmente, de um lado, e as ações políticas de coletividades humanas, de outro (BAUMAN, 2001, p. 12).

Bauman (1998) infere que as mudanças emergentes na sociedade atual, tanto de cunho político, econômico, social, educacional e cultural, têm causado o mal-estar da pós-

\footnotetext{
${ }^{1}$ Expressão lançada por Bauman (2001) na virada do século XXI, descrevendo as transformações observadas na sociedade moderna e a diluição dos parâmetros sociais que, até então, mostravam-se sólidos, enrijecidos, estáveis e ordenados.
} 
modernidade, destacando-se algumas características marcantes, como: insegurança, incerteza, desconfiança, medo, ansiedade, baixa tolerância à frustração, egocentrismo, embotamento afetivo, entre outras. Mediante tais características, emerge um sujeito egoísta, centrado em si mesmo e na satisfação de suas necessidades, pouco interessado em organizar a nova desordem do mundo e se envolver com o coletivo e com os problemas sociais.

Diante dos excessos, dos tensionamentos, das transformações e da complexidade da vida social na contemporaneidade, observam-se novas percepções e configurações de tempo, espaço, lugar e não lugar. Para além da compreensão de lugar como mera localização geográfica, Tuan (2013) compreende-o como espaço do vivido, do experienciado, a partir da relação do sujeito com os seus espaços de vida social. Ao colocar em evidência a questão do lugar, o autor considera o vínculo afetivo que se estabelece na relação do homem com o espaço e as múltiplas experiências que transformam este espaço em lugar.

Nessa perspectiva, o espaço pode transformar-se em lugar, entrelaçando-se com os preceitos da experiência, conforme assevera Tuan (2013, p. 14): “O que começa como espaço indiferenciado transforma-se em lugar à medida que o conhecemos melhor e o dotamos de valor." Ou seja, é a partir da dimensão humana, da relação de afeto e, especialmente, da experiência individual que se tem a emergência de lugar.

Em relação ao conceito de experiência, Larrosa (2002, p. 25) propõe que

\begin{abstract}
A experiência é em primeiro lugar um encontro ou uma relação com algo que se experimenta, que se prova. O radical é periri, que se encontra também em periculum, perigo. A raiz indo-europeia é per, com a qual se relaciona antes de tudo a ideia de travessia, e secundariamente a ideia de prova. [...] Em nossas línguas há uma bela palavra que tem esse per grego de travessia: a palavra peiratês, pirata. O sujeito da experiência tem algo desse ser fascinante que se expõe atravessando um espaço indeterminado e perigoso, pondo-se nele à prova e buscando nele sua oportunidade, sua ocasião. A palavra experiência tem o ex de exterior, de estrangeiro, de exílio, de estranho e também o $e x$ de existência. A experiência é a passagem da existência, a passagem de um ser que não tem essência ou razão ou fundamento, mas que simplesmente "ex-iste" de uma forma sempre singular, finita, imanente, contingente.
\end{abstract}

Para Tuan (2013), experiência relaciona-se à capacidade do sujeito aprender a partir de suas próprias vivências, constituindo-se de sentimentos, valores e pensamentos. Sendo assim, a questão temporal articula-se à conceituação anterior, uma vez que tempo tem relação com experiência e, consequentemente, com lugar. Valendo-se de três vertentes, o autor explora a dimensão de tempo e lugar, assinalando "[...] tempo como movimento ou fluxo, e lugar como pausa na corrente temporal; afeição pelo lugar como uma função de tempo, captada na frase: 'leva tempo para se conhecer um lugar'; e lugar como tempo tornado visível, ou lugar como lembrança de tempos passados" (TUAN, 2013, p. 219). 
Entrecruzando o exposto, inferimos que os marcos no tempo constituem o lugar. Entretanto, Tuan (2013, p. 219) faz referência à "pausa no movimento." Essa pausa possibilita envolvimento e apreciação maior do sujeito com o espaço, possibilitando a emergência de uma pluralidade de experiências e significações. Complementarmente, Augé (2012) enfatiza que no lugar afirmam-se as características identitárias, relacionais e históricas.

Associando essas linhas de raciocínio à concepção de experiência apresentada por Larrosa (2002, p. 21): “[...] o que nos passa, o que nos acontece, o que nos toca. Não o que se passa, não o que acontece, ou o que toca”, podemos afirmar, de fato, que lugar é o espaço da experiência, como já anunciado por Tuan (2013).

Assim como Augé (2012) destaca os excessos como constituintes das transformações da sociedade contemporânea, Larrosa (2002) os descreve como responsáveis por dificultar a experiência nos tempos atuais, referindo-se ao excesso tanto de informação quanto de opinião e trabalho, o que resulta na falta de tempo.

Apesar do bombardeio de excessos vivenciados, Larrosa (2002, p. 24) alerta sobre a importância do "sujeito moderno" ser também o sujeito da experiência, o que, segundo ele,

[...] requer um gesto de interrupção, um gesto que é quase impossível nos tempos que correm: requer parar para pensar, parar para olhar, parar para escutar, pensar mais devagar, olhar mais devagar, e escutar mais devagar; parar para sentir, sentir mais devagar, demorar-se nos detalhes, suspender a opinião, suspender o juízo, suspender a vontade, suspender o automatismo da ação, cultivar a atenção e a delicadeza, abrir os olhos e os ouvidos, falar sobre o que nos acontece, aprender a lentidão, escutar aos outros, cultivar a arte do encontro, calar muito, ter paciência e dar-se tempo e espaço.

Vale ressaltarmos que a qualidade, a significação e a intensidade das experiências dizem muito a respeito da relação que se estabelece com o lugar, não sendo possível mensurarmos cronologicamente o tempo necessário para que determinado espaço tenha uma dimensão afetiva de lugar.

Considerando o que fora exposto, Augé (2012) defende a hipótese de que, não sendo possível a vivência da experiência, do lugar identitário, relacional e histórico, tem-se a emergência dos não lugares, os quais têm sido produzidos, especialmente, no contexto da sociedade contemporânea. Para o autor, os não lugares são espaços que se caracterizam pela transitoriedade, pela ausência de sentido, de vínculos relacionais, de identidade e de memória, estando " [...] prometido à individualidade solitária, à passagem, ao provisório e ao efêmero [...]" (p. 74).

Como exemplo de não lugares, podemos destacar aeroportos, estações, pontos de trânsito, ruas comerciais, parques de lazer, entre outros. Todos esses espaços são tomados pelo 
excesso de informação, de imagens e textos que, de certo modo, intensificam as relações de consumo, dificultam a emergência da identidade singular e criam solidão. Dessa forma, estimulam a individualidade narcísica num cenário que parece expressar algo comum: “[...] fazer como os outros para ser você mesmo" (AUGÉ, 2012, p. 98).

A diferença de lugar e não lugar está atrelada à noção de lugar e espaço. Nesse sentido, Certeau (2002, p. 202) propõe que “[...] o espaço é um lugar praticado. Assim a rua geometricamente definida por um urbanismo é transformada em espaço pelos pedestres" (grifo do autor).

Tomando, pois, a noção de movimento e vivência do sujeito no espaço, Augé (2012, p. 77) inclui no lugar antropológico "[...] a possibilidade dos percursos que nele se efetuam, dos discursos que nele se pronunciam e da linguagem que o caracteriza". Por conseguinte, as experiências do sujeito, tanto individuais quanto coletivas, tecem histórias que dizem muito sobre sua relação com os espaços, lugares e/ou não lugares. Dito de outro modo, a ação do sujeito, mobilizada pelo seu modo de "caminhar" e pela linguagem, atribui novos sentidos aos espaços.

\section{0 "lugar" infância e criança}

No contexto abordado por Tuan (2013), em que os marcos no tempo constituem o lugar, cuja "pausa no movimento" possibilita uma pluralidade de experiências e significações, e na indicação de Augé (2012) que é no lugar que se afirmam as características identitárias, relacionais e históricas, questionamos acerca de qual o lugar (ou não lugar) infância e criança. Há lugar para infância e criança na contemporaneidade?

Embora muitas vezes utilizada de maneira indissociada, a definição de infância e criança têm suas particularidades, ocupando diferentes lugares ao longo do tempo e da história. Para a Sociologia da Infância, de acordo com Sarmento (2005, p. 371), há uma distinção semântica e conceptual entre infância e criança. A primeira relaciona-se à categoria social do tipo geracional, já a segunda refere-se " [...] ao sujeito concreto que integra essa categoria geracional e que, na sua existência, para além da pertença a um grupo etário próprio, é sempre um actor social que pertence a uma classe social, a um género etc.” Segundo Carvalho e Schwengber (2014), mesmo com variações sociais e culturais, o sujeito criança refere-se a uma faixa etária específica, que, no caso do Brasil, conforme estabelece o Estatuto da Criança e do Adolescente (ECA), compreende o período de zero a doze anos. 
Nesse viés teórico, percebemos que a concepção de infância faz parte de um longo processo de construção histórico e social, uma vez que tem se mostrado de modo singular em diferentes épocas e culturas e em concordância com diferentes cenários: social, econômico, religioso e intelectual.

\begin{abstract}
A infância é historicamente construída, a partir de um processo de longa duração que lhe atribuiu um estatuto social e que elaborou as bases ideológicas, normativas e referenciais do seu lugar na sociedade. Esse processo, para além de tenso e internamente contraditório, não se esgotou. É continuamente actualizado na prática social, nas interações entre crianças e nas interacções entre adultos e crianças. [...] A geração da infância está, por consequência, num processo contínuo de mudança, não apenas pela entrada e saída dos seus actores concretos, mas por efeito conjugado das acções internas e externas dos factores que a constroem e das dimensões de que se compõe (SARMENTO, 2005, p. 365-366).
\end{abstract}

Conforme sinaliza Kuhlmann Jr. (1998), etimologicamente, a palavra infância originase do latim infantia e significa incapacidade de falar. No período medieval, essa incapacidade estaria relacionada à primeira infância, podendo se estender até os sete anos, momento em que a criança domina a palavra, passando, a partir daí, a fazer parte da idade da razão.

Todavia, segundo Ariès (2018), a infância é uma criação da Europa Ocidental, no início dos tempos modernos, visto que "Até por volta do século XII, a arte medieval desconhecia a infância ou não tentava representa-la. É [...] provável que não houvesse lugar para a infância neste mundo" (p. 17).

Os cuidados especiais que as crianças recebiam naquela época eram reservados apenas aos primeiros anos de vida, período em que elas necessitavam dos cuidados físicos à sua sobrevivência. Assegurado seu desenvolvimento, a criança passava a ser tratada como adulto em miniatura, convivendo diretamente com os mais velhos, que transmitiam-lhe valores e costumes. Nessa forma coletiva de vida, misturavam-se idades e condições sociais distintas (ARIÈS, 2018).

Dito de outro modo, inferimos que não havia uma diferença clara entre o mundo adulto e o mundo infantil, nem mesmo em relação à vestimenta e à vida social. As crianças pobres eram inseridas no trabalho e as mais abastadas tinham o privilégio de receber preparo e educação para a vida adulta. Nesse período, eram poucas as escolas, algumas ligadas à igreja e outras de origem particular, nas quais estudavam meninos de diferentes idades.

Importante ressaltarmos que, do século XV até meados do século XVII, a exclusão das mulheres na educação escolar era notadamente marcante. As meninas eram treinadas para se comportarem, desde muito cedo, como adultas, especialmente em relação aos afazeres domésticos, sendo hábito comum, na época, enviá-las a conventos para instrução 
exclusivamente religiosa. Em consequência, as mulheres eram praticamente semianalfabetas. (ARIÈS, 2018).

Por volta do século XVIII, com o desenvolvimento do capitalismo e das novas exigências sociais, um novo modelo de família e de vida privada foi instituído. Por extensão, ocorreram mudanças no relacionamento entre pais e filhos, e a criança passou a ocupar um lugar central na dinâmica familiar. Logo, sua educação foi mais valorizada. Nesse contexto, a institucionalização da criança surge na Europa, principalmente na Inglaterra, no período industrial, com o estabelecimento das classes sociais e a emergência da família moderna.

Sob influência dos reformadores moralistas, a aprendizagem social das crianças deixou de ser realizada pelo convívio direto com os adultos, sendo substituída pela educação escolar, atendendo às necessidades que a cultura letrada exigia. Ou seja, a escola, no início dos tempos modernos, assume a função de "[...] isolar cada vez mais as crianças durante um período de formação tanto moral como intelectual, de adestrá-las graças a uma disciplina mais autoritária, e, desse modo, separá-las da sociedade dos adultos" (ARIÈS, 2018, p. 107).

Para Sarmento (2005), tanto a segregação do mundo dos adultos quanto a institucionalização das crianças contribuíram consideravelmente para a construção simbólica da concepção de infância na modernidade como sinônimo de dependência e fragilidade. No entanto, esse constructo está atrelado aos processos de disciplinação da infância, operando com a “[...] imposição de modos paternalistas de organização social e de regulação dos cotidianos, o desapossamento de modos de intervenção e a desqualificação dos seus mundos de vida e a colonização adultocentrada dos modos de expressão e de pensamento das crianças" (SARMENTO, 2005, p. 369-370).

Como infere Heywood (2004), entre os séculos XVIII e XIX, é lançado um olhar romantizado sobre a infância, retomando-se os preceitos de John Locke (1632-1704) e Jean Jacques-Rousseau (1712-1778). O primeiro por minimizar os efeitos da ideia do "pecado original" e difundir a visão de criança como tábula rasa, dando ênfase ao papel do educador como transmissor do conhecimento e do rigor físico e intelectual na educação do sujeito. Já o segundo por idealizar a infância e defender suas peculiaridades, afirmando que a criança, em seu estado natural, é pura, dócil e inocente, sendo a sociedade responsável por corrompê-la. Naquele período, foi marcante, portanto, a ideia cristalizada de uma infância ingênua e de uma natureza infantil abstrata, supostamente universal. Não obstante, mesmo de forma velada, essa ideia ainda tem seus reflexos na atualidade.

Com o advento da modernidade e o avanço da ciência, propagam-se novos conhecimentos em relação à infância, especialmente no que tange ao desenvolvimento e à 
aprendizagem da criança. Pautando-se em padrões de normalidade e homogeneidade, diversas áreas do saber, especialmente a Biologia, a Psicologia e a Pedagogia, fazem emergir um conjunto de teorias e práticas, com o propósito de atender e educar as crianças a partir dos preceitos de uma infância normal.

As inúmeras transformações que se apresentam no cenário contemporâneo, relacionadas ao tempo, ao lugar, à cultura, às relações sociais, entre outras, acenam novos significados e vivências em relação à infância. Nessa perspectiva, para conceituarmos infância precisamos levar em consideração os contextos social e cultural nos quais as crianças se inserem, bem como as questões de gênero, etnia, classe social, entre outras.

Nesse sentido, pensarmos em infâncias e não apenas em infância é fundamental, uma vez que não há uma concepção singular que a represente, como enfatizam Carvalho e Schwengber (2014, p. 391): “As pedagogias culturais, as múltiplas configurações familiares, as tecnologias da informação e da comunicação são alguns dos processos que nas sociedades atuais têm contribuído para a constituição de novas e diferentes infâncias."

Ao desenvolver estudos sobre a infância, Kramer (2011) compreende a criança como um sujeito social, que produz cultura e nela é produzida, imersa na historicidade do seu tempo e no contexto das relações sociais. Portanto, ao considerarmos a condição de vida da criança afirmamos a existência de uma multiplicidade de infâncias e de crianças, situando os diferentes contextos nos quais estão inseridas, posto que

[...] O conjunto das experiências vividas por elas em diferentes lugares históricos, geográficos e sociais é muito mais do que uma representação dos adultos sobre esta fase da vida. É preciso conhecer as representações de infância e considerar as crianças concretas, localizá-las como produtoras da história (KUHLMANN JR., 1998, p. 30).

Apesar das transformações históricas e sociais, o "lugar" infância e criança na contemporaneidade ainda apresenta resquícios das concepções do passado. Ao colocar em evidência o contexto atual, Kramer (2011) aponta as contradições sociais que marcam o cenário contemporâneo, tecendo inquietações sobre como isso se reflete na relação e no trato com as crianças. Ou seja,

\footnotetext{
Como propiciar que deixem de ser in-fans (aquele que não fala), para que adquiram voz e poder num contexto que, de um lado, infantiliza jovens e adultos e empurra para frente o momento da maturidade e, de outro, os 'adultiza', jogando para trás a curta etapa da primeira infância? (KRAMER, 2011, p. 101).
}

Ao mesmo tempo que provoca inquietações, a autora acena para a possibilidade de trabalharmos sob a perspectiva de humanização, de experiências, de leituras do mundo e escrita da história coletiva, com práticas solidárias entre crianças e adultos. Nessa envergadura, a 
Educação Infantil se apresenta como lugar importante para fazer diferente, partindo do olhar cuidadoso sobre cada criança, da valorização dos seus direitos e do reconhecimento de sua voz social.

\section{A educação infantil como "lugar" de experiência}

Ao alinhavarmos a construção histórica do conceito de infância à contemporaneidade, percebemos o quão é importante refletirmos sobre o lugar da Educação Infantil neste novo contexto, analisando os "pontos" (retos, cruzados, entrecruzados, atados) utilizados em sua tessitura.

Nas últimas duas décadas, estudos que evidenciam a Educação Infantil vêm ganhando destaque, assinalando as mudanças advindas das políticas públicas e do atendimento educacional das crianças entre 0 e 5 anos. No entanto, o caráter assistencialista e compensatório que embasou o trabalho nas creches e pré-escolas até a década de 1980 ainda tem seus reflexos na atualidade.

Tanto a Constituição Federal de 1988 (BRASIL, 1988) quanto o Estatuto da Criança e do Adolescente (ECA), promulgado em 1990, foram frutos de intensa mobilização política da população e representam avanços legais importantes para a atenção à infância, embora suas diretrizes não tenham se tornado, de fato, realidade (KRAMER, 2011).

A Constituição Federal de 1988 é o primeiro documento a reconhecer a Educação Infantil como direito das crianças de 0 a 6 anos de idade, dever do Estado e direito da família. Já o ECA reconhece os direitos legais da criança e do adolescente e aponta a responsabilidade conjunta da família, da sociedade e do Estado na formação integral da criança, de modo a assegurar o direito à vida, saúde, educação, cultura, lazer, entre outros direitos.

Em 1996, a Lei de Diretrizes e Bases da Educação Nacional (LDB) prescreve a Educação Infantil como primeira etapa da Educação Básica, devendo integrar-se ao sistema de ensino. Em 2001, o Plano Nacional de Educação (PNE) lança metas importantes à ampliação e à qualificação dessa modalidade de ensino (BRASIL, 2001).

No ano de 2006, por meio da Lei $\mathrm{n}^{\circ}$ 11.274, o Governo Federal amplia o tempo do Ensino Fundamental de oito para nove anos e a Educação Infantil passa a atender a faixa etária de 0 a 5 anos. No entanto, apesar de a Educação Infantil constituir-se como um direito de todas as crianças e dever do Estado, o atendimento às crianças de 4 e 5 anos torna-se obrigatório apenas com a Emenda Constitucional n ${ }^{\circ}$ 59, no ano de 2009 (BRASIL, 2009). 
Pelo fato de a Educação Infantil ser compreendida como a primeira etapa da Educação Básica, desempenha um papel importante no desenvolvimento da criança, no estabelecimento das relações sociais fora do ambiente familiar e nos fundamentos do processo educacional. Em relação a esses aspectos basilares, as Diretrizes Curriculares Nacionais para a Educação Infantil (DCNEI) sinalizam que

[...] o campo da Educação Infantil vive um intenso processo de revisão de concepções sobre educação de crianças em espaços coletivos, e de seleção e fortalecimento de práticas pedagógicas mediadoras de aprendizagens e do desenvolvimento das crianças. Em especial, têm se mostrado prioritárias as discussões sobre como orientar o trabalho junto às crianças de até três anos em creches e como assegurar práticas junto às crianças de quatro e cinco anos que prevejam formas de garantir a continuidade no processo de aprendizagem e desenvolvimento das crianças, sem antecipação de conteúdos que serão trabalhados no Ensino Fundamental (BRASIL, 2009, p. 7).

Legalmente, há uma preocupação com o desenvolvimento e a aprendizagem da criança, de modo que se respeite as especificidades da infância e valorize as experiências cotidianas da criança, inibindo que ela seja exposta aos processos rígidos de escolarização. Todavia, nos questionamos: Como, de fato, a criança contemporânea vive a sua infância? Como o lugar Educação Infantil tem tratado as infâncias e as crianças?

Larrosa (2011) parece nos ajudar a refletir a esse respeito. Contrapondo-se à ideia de infância como "paraíso perdido" ou "matéria prima para a fabricação de um mundo novo", recorrente no imaginário social, o autor propõe a infância como "figura de acontecimento", que escapa a qualquer integração e identidade, uma vez que “[...] não pode ser integrado, nem identificado, nem compreendido, nem previsto.” (p. 282). Neste caso, acontecimento é sinônimo de tempo presente, de novidade, surpresa, começo, criação, liberdade, entre outros termos equivalentes. Portanto,

A criança não é nem antiga nem moderna, não está nem antes nem depois, mas agora, atual, presente. Seu tempo não é linear, nem evolutivo, nem genético, nem dialético, nem sequer narrativo. A criança é um presente inatual, intempestivo, uma figura do acontecimento. E só a atenção ao acontecimento, como o incompreensível e o imprevisível, pode levar a pensar uma temporalidade descontínua (LARROSA, 2011, p. 284).

Na visão de Agamben (2005), é necessário o rompimento do paradigma de criança frágil e incapaz, considerando a sua condição de experiência e transformação. Para o autor, a in-fância se encontra antes mesmo da palavra e da própria linguagem, embora infância e linguagem pareçam estar envoltas num círculo que remete a origem de uma à outra. Entretanto, é, possivelmente, 
[...] neste círculo que devemos procurar o lugar da experiência enquanto infância do homem. Pois a experiência, a infância que aqui está em questão, não pode ser simplesmente algo que precede cronologicamente a linguagem e que, uma certa altura, cessa de existir para versar-se na palavra [...] (AGAMBEN, 2005, p. 58).

Tanto Larrosa $(2011,2017)$ quanto Agamben (2005) tratam a infância como lugar aberto à experiência, o que possibilita que a criança, imersa numa rede de relações, construa a sua palavra e tenha condições de expressar-se sobre si. Amparando-se nessa perspectiva teórica e levando em consideração que os espaços educativos devem possibilitar que a criança se torne "sujeito da experiência" (LARROSA, 2002), mobilizada pelo diálogo, pela troca, pela crítica, pela vivência e interação humana, compreendemos a Educação Infantil como "lugar" de experiência.

Ao se referir à educação, Larrosa (2011, p. 285) a relaciona como figura da descontinuidade, “[...] que se encarregue de uma experiência libertadora da historicidade humana, que permita pensar o acontecimento não como determinação, mas como liberdade. Um pensamento da educação que seja, ao mesmo tempo, libertação do passado e abertura do porvir." Daí a importância das instituições educativas valorizarem o potencial criativo de cada criança, desprendendo-se da linearidade do tempo, da padronização de comportamentos e do controle da infância, compreendendo a sua condição de ser criança.

Reconhecer a existência de uma pluralidade de infâncias implica refletir sobre a complexidade das práticas educativas, uma vez que cada criança é única e tem uma história singular, com percursos familiares e culturais diferentes. Portanto,

[...] a infância nunca é o que sabemos (é o outro dos nossos saberes), mas, por outro lado, é portadora de uma verdade à qual devemos nos colocar à disposição de escutar; nunca é aquilo apreendido pelo nosso poder (é o outro que não pode ser submetido), mas ao mesmo tempo requer nossa iniciativa; nunca está no lugar que a ela reservamos (é o outro que não pode ser abarcado, mas devemos abrir um lugar para recebê-la. Isso é a experiência da criança como um outro: [...] é a atenção à presença enigmática da infância [...] (LARROSA, 2017, p. 232).

Na esteira do que fora explicitado, infere-se que a Educação Infantil não pode curva-se à lógica adultocêntrica, que universaliza os modos de ser criança e a destitui do seu papel social. Distintamente, ao assumirem-se como "lugar" de experiência, os espaços educativos possibilitam novos olhares e sentidos sobre as infâncias, promovendo o reconhecimento e o protagonismo da criança no tempo presente. 


\section{Algumas considerações}

Compreender como o conceito de infância e de criança foi construído ao longo da história possibilita-nos refletir sobre como a infância vem sendo pensada, tratada e cerceada na atualidade. Portanto, embora se apresente como categoria social, faz-se ainda necessário romper com alguns paradigmas sociais, desnaturalizando a ideia de infância e reconhecendo as condições de vida de cada criança.

Tomando a Educação Infantil como um direito da criança e considerando seu papel importante para o desenvolvimento do sujeito e para o estabelecimento de relações sociais, é fundamental qualificar e valorizar cada vez mais este lugar.

Conceituando lugar, a partir de Tuan (2013) e Augé (2012), como sinônimo de experiência, de diferentes percursos, de historicidade, de novas significações, de identidade, de vínculo afetivo, de interações sociais, de reconhecimento, de linguagens e de discursos, é imperativo afirmar a Educação Infantil como "lugar" de experiência, oportunizando que cada criança viva sua infância de forma plena e seja valorizada em sua singularidade, podendo expressar-se sobre si e ser reconhecida como sujeito social.

\section{Referências}

AGAMBEN, G. Infância e história: destruição da experiência e origem da história. Belo Horizonte: UFMG, 2005.

AGAMBEN, G. O que é o contemporâneo? e outros ensaios. Chapecó, SC: Argos, 2009.

ARIÈS, P. História social da criança e da família. 2. ed. [reimpr.]. Rio de Janeiro: LTC, 2018.

AUGÉ, M. Não lugares: introdução a uma antropologia da supermodernidade. 9. ed.

Campinas, SP: Papirus, 2012.

BAUMAN, Z. O mal-estar da pós-modernidade. Rio de Janeiro: Jorge Zahar Editor, 1998.

BAUMAN, Z. Modernidade líquida. Rio de Janeiro: Jorge Zahar Editor, 2001.

BRASIL. Constituição da República Federativa do Brasil de 1988. Brasília, DF: Presidência da República, [2016]. Disponível em: http://www.planalto.gov.br/ccivil_03/Constituicao/ Constituiçao.htm. Acesso em: 3 nov. 2021.

BRASIL. Lei $n^{o} 8.069$, de 13 de julho de 1990. Dispõe sobre o Estatuto da Criança e do Adolescente e dá outras providências. Diário Oficial da República Federativa do Brasil. Brasília, DF, 16 jul. 1990. Disponível em: http://www.planalto.gov.br/ccivil_03/Leis/L8069.htm. Acesso em: 5 nov. 2021. 
BRASIL. Lei $n^{\circ}$ 9.394, de 20 de dezembro de 1996. Estabelece as diretrizes e bases da educação nacional. Diário Oficial [da] República Federativa do Brasil, Brasília, DF, 20 dez. 1996. Disponível em: www.planalto.gov.br/ccivil_03/LEIS/19394.htm. Acesso em: 5 nov. 2021.

BRASIL. Lei $n^{o} 10.172$, de 9 de janeiro de 2001. Aprova o Plano Nacional de Educação e dá outras providências. Diário Oficial [da] República Federativa do Brasil. Brasília, DF, 10 jan. 2001. Disponível em: http://www.planalto.gov.br/ccivil_03/LEIS/LEIS_2001/L10172.htm. Acesso em: 10 nov. 2021.

BRASIL. Lei $n^{o}$ 11.274, 6 de fevereiro de 2006. Altera a redação dos arts. 29, 30, 32 e 87 da Lei $\mathrm{n}^{\circ}$ 9.394, de 20 de dezembro de 1996, que estabelece as diretrizes e bases para a educação nacional, dispondo sobre a duração de 9 (nove) anos para o ensino fundamental, com matrícula obrigatória a partir dos 6 (seis) anos de idade. Diário Oficial [da] República Federativa do Brasil. Brasília, DF, 7 fev. 2006. Disponível em: http://www.planalto.gov.br/ccivil_03/_Ato2004-2006/2006/Lei/L11274.htm. Acesso em: 12 nov. 2021.

BRASIL. Emenda constitucional $n^{\circ}$ 59, de 11 de novembro de 2009. Diário Oficial [da] República Federativa do Brasil. Brasília, DF, 12 nov. 2009. Disponível em: http://www.planalto.gov.br/ccivil_03/constituicao/Emendas/Emc/emc59.htm. Acesso em: 4 nov. 2021.

BRASIL. Ministério da Educação. Secretaria de Educação Básica. Diretrizes curriculares para a educação infantil - DCNEI. Conselho Nacional de Educação. Câmara de Educação Básica. Brasília, DF: MEC, SEB, 2009. Disponível em: http://portal.mec.gov.br. Acesso em: 5 nov. 2021.

CARVALHO, R. S.; SCHWENGBER, M. S. V. Infâncias e crianças na contemporaneidade. In: GONZÁLEZ, F. J.; FENSTERSEIFER, P. E. (orgs.). Dicionário crítico de Educação Física. 3. ed. rev. e ampl. Ijuí, RS: Editora Unijuí, 2014.

CERTEAU, M. A invenção do cotidiano: 1. Artes de fazer. 8. ed. Petrópolis, RJ: Vozes, 2002.

HEYWOOD, C. Uma história da infância. Porto Alegre: Artmed, 2004.

KRAMER, S. Infância, cultura contemporânea e educação contra a barbárie. In: BAZÍLIO, L. C.; KRAMER, S. Infância, educação e direitos humanos. 4. ed. São Paulo: Cortez, 2011.

KUHLMANN JR., Moysés. Infância e educação infantil: uma abordagem histórica. Porto Alegre: Mediação, 1998.

LARROSA, J. Notas sobre experiência e o saber da experiência. Revista Brasileira de Educação, n. 9, jan./fev./mar./abr. 2002.

LARROSA, J. Dar a palavra. Notas para uma dialógica da transmissão. In: LARROSA, J.; SKLIAR, C. Habitantes de Babel: políticas e poéticas da diferença. 2. ed. Belo Horizonte: Autêntica, 2011. 
LARROSA, J. O enigma da infância: ou o que vai do impossível ao verdadeiro. In:

LARROSA, J. Pedagogia profana: danças, piruetas e mascaradas. 6. ed. rev. ampl. Belo Horizonte: Autêntica, 2017.

SARMENTO, M. J. Gerações e alteridade: interrogações a partir da sociologia da infância. Educação \& Sociedade, Campinas, v. 26, n. 91, p. 361-378, maio/ago. 2005.

TUAN, Y-F. Espaço e lugar: a perspectiva da experiência. Londrina: Eduel, 2013. 